\title{
Digital Entrepreneurship and Agile Methods-A Hackathon Case Study
}

\author{
Nancy Richter and Djanina Dragoeva
}

\begin{abstract}
"What if, when they ask 'Alexa, where can I do something here tonight?', travellers no longer receive the answer 'I don't know'? And, could start-ups use all tourist data freely and without restriction to develop innovative applications for travellers at any time?" ("German National Tourist Board", n.d.). These and similar questions are currently being asked by those responsible for tourism marketing and product development, such as destination management organisations (DMO: "Public or public-private entity whose aim is to foster, plan and coordinate the tourism development of a destination as a whole".) ("IGI Global", n.d.) in Germany. In particular, the travel destination Thuringia sees itself as a pioneer on topics such as AI, decentralised data structures and new types of interactions: "We were looking for a way to make the data of Thuringian tourism up-to-date, findable and freely usable and thus provide the path for open innovation and new technologies." (Detlef Klinge, Thüringer Tourismus GmbH retrieved from "German National Tourist Board", n.d.). To meet these challenges, the DMO relies on the processing of open data in a tourist content architecture and on entrepreneurial management methods such as the hackathon. This method, in turn, must be embedded in a holistic management approach; otherwise, creative results will be lost even before they come to the market. The question is how these technologies and management methods must be implemented in DMOs so that they generate sustainable competitive advantages and customer benefits for the respective travel destination.
\end{abstract}

\author{
N. Richter $(\bowtie)$ \\ University of Applied Sciences, Schmalkalden, Germany \\ e-mail: n.richter@hs-sm.de \\ D. Dragoeva \\ Bauhaus University, Weimar, Germany \\ (C) The Author(s) 2021
}

M. Soltanifar et al. (eds.), Digital Entrepreneurship, Future of Business and Finance,

https://doi.org/10.1007/978-3-030-53914-6_3 


\section{Introduction: The Development of the Tourism Market}

The travel market is saturated and has long since developed into a buyer's market. Marketing has therefore played an important role for tourism providers since the mid-1970s. At the turn of the millennium, the Internet began to turn the travel industry upside down. Travel portals have influenced travel decisions since the late 1990s. Especially, the launch of lastminute.com in 1998 was one of the defining inventions of online travel. The company still sells last minute package deals at short notice which is a great advantage over traditional agents. This was followed by digital content platforms for the display of photos and videos, social networks, digital travel portals, geo-targeting, the virtualisation of reality (VR) and the expansion of reality (AR) ("Tourismuszukunft", n.d.). These developments have an impact not only on travel decisions, but also on travel arrangements during a trip. Digital technologies have changed the entire customer journey. ${ }^{1}$ But the development does not stop there. Artificial intelligence (AI), decentralised data structures and the associated evolution of customer interaction will transform customer journeys even more extensively. These developments offer numerous opportunities. At the same time, these processes are extremely challenging for the industry. Representatives of the industry are already using digitalisation options, but complain about the lack of financial resources, the lack of know-how, the lack of quality of content from the individual companies and the lack of broadband when implementing digital instruments (Statista 2019).

The tourism industry is characterised by small-scale provider structures and a high level of complexity of tourism service packaging (Freyer 2015). Many individual organisations are involved in the creation of a single tourist product. Packages could combine for example transport, accommodations, meals, attractions and entertainment. With the latest digital developments, the provision of tourism service packages becomes more personalised and multichannel (Keller et al. 2017). Travellers receive a more active role and co-create their travel experience in real time using different channels. Given these developments, DMOs need to consider a strategic realignment. In order to support digital innovation, they need to become digital platforms to improve the travel experience for their guests. The chapter will present a case study on how DMOs in Germany currently deal with developments related to artificial intelligence and decentralised data structures. Further, it will be asked if an open data hackathon is a suitable approach to help ensure the competitiveness of tourist destinations. These questions will be answered by analysing a hackathon case study.

How are the current developments around artificial intelligence and decentralised data structures changing tourism?

\footnotetext{
${ }^{1}$ Customer Journey: Customer journey refers to the path followed by a customer via so-called touchpoints before making a purchase decision (Yachin 2018).
} 


\section{Artificial Intelligence and Linked Open Data Create Smart Destinations}

Machine-readable data in the form of linked open data (LOD) and artificial intelligence (AI) as a generic term for different automated computing methods and machine learning (ML) are directly related. But what do these terms have in common and what do they have to do with tourism? With the help of ML, patterns can be recognised in data to derive predictions (Horster and Kärle 2019a). Data is processed based on computing models or algorithms. The more data is processed, the better the algorithm becomes. The algorithm develops independently after several rounds, therefore one speaks of AI. A machine is particularly good at interpreting data that is structured in a uniform language or ontology, e.g. schema. org. The structuring and the provision of a large amount of data, such as POI, events, hotels and personal preferences of the guests, and their connection through AI algorithms, enable interesting basic applications for tourism (Samochowiec et al. 2019).

In the future, a smart assistant will be able to use the data to answer individual inquiries from guests or to give tips and will be available at any time when travelling. Automated access at events, cashless payment in event parks, navigation on ski slopes or real-time information on the smart watch at the holiday location are also conceivable (Horster and Foltin 2020). To enable this scenario, however, destination management organisations have to become digital platforms to connect the offers of the destination with the guest and his or her preferred devices like smartphones, laptop computers, tablets or smart watches.

\section{Knowledge Graphs depict Tourism Reality}

People and machines can intuitively capture data that is represented in a knowledge graph or a graph database as a network structure (Paulheim 2016). A knowledge graph describes real entities such as a hotel and a review about it, as well as the relationships of these entities to each other (Horster and Kärle 2019b). The knowledge graph is semantic because the data is given meaning. This means that a smart assistant such as Alexa becomes better at understanding what specific information is meant when a traveller asks for it. In this way, a digital image of the touristic reality is created piece by piece. The knowledge graph can be filled infinitely with data and their relevant context and is able to gradually recognise relationships between these data automatically. This is a great advantage over previous relational databases, the entries of which can later be changed or supplemented only with great difficulty and where the data has little relationship to one another (Horster and Kärle 2019b). With the help of knowledge graphs, data can be transformed into information, which can then be transformed into knowledge and lead to actions by the guest (Stichbury 2017). Initially, only individual data is available, for example for a hotel or bike path. This data can be aggregated and assigned to addresses, opening hours or special offers, and then all these entities can be related to each other. Data relationships between a hotel and a bike path then help a guest to decide in real time where to stay at night, or if there is something special near his or her location. Knowledge graphs thus have a real-time influence on the specific guest behaviour during the customer journey. 


\section{The Evolution of the Web 3.0}

With the developments described above, the World Wide Web is changing into a semantic Web or Web 3.0 (Kinlan 2016; Horster and Kärle 2019c). The future development, especially in tourism, is that travellers will receive answers and recommendations in real time, depending on the provider, interest and output device. To realise this, machines have to be able to interpret data. For users, it is becoming increasingly irrelevant where the data comes from and via which channel (Sommer 2018). The classic web design takes a back seat, and DMOs have to focus on the data architecture instead of on their websites ("semantify", n.d.). Large players such as Google or Facebook are currently driving these developments. The Google Knowledge Graph, which now provides answers to questions without listing websites at the top of the results of a Google search, makes this all too clear. If you enter terms in the Google search engine, you increasingly get an overview at the top of the search results page. Voice assistants are going in a similar direction, providing answers instead of links. In this way, large platforms build "walled gardens", a web on the web that the user no longer has to leave to receive information. The advantages for the user or traveller are obvious, but the tourist actors and DMOs are increasingly invisible as senders of messages, unless they store their details in the designated virtual locations and an appropriate data format, for example, Google My Business. Destinations could make company data and further information such as events and information on hiking trails available in the same way on the entire web, to break up the power of the walled gardens and to create a web or a data basis that is open to anyone. On the other hand, the use or labelling of data in formats like schema.org also helps to increase the visibility of a DMO on large platforms, as they and their information are displayed more prominently (Hauer 2020).

\subsection{How Do Tourism Destinations in Germany deal with Al, Decentralised Data Structures and New Types of Interactions in the Web 3.0?}

Tourism is one of the most "affected" sectors when it comes to digitisation. It appears that the industry has lost control of the data. The big players Google and Facebook, or travel platforms such as TripAdvisor, are striving for information monopolies or already have them. Travellers are using these and other channels to obtain information about their trips and are not very interested in where the information comes from. This is also supported by the falling number of visitor clicks on the destination websites. The data flow is establishing itself as increasingly more important than the data channel (Sommer 2018, p. 4). Another challenge for tourism is the purely technical one: "There is a fragmented picture of different data formats with very varying levels of detail and often severely restricted possibilities for data use. Harmonisation is difficult, but would make it much easier" (Sommer 2018, p. 5). 
Organisationally, however, a decision has to be made regarding who will take care of this "data infrastructure" and how it will be managed. This is the biggest challenge. The goal is to create and provide valuable and readily available data (Sommer 2018, p. 5). The formula is clear: the higher the quality, the greater the value of the data is. However, the rapid pace of this change requires a rapid change in management that not every single tourist information office or every single company or service provider can solve on its own. A central content architecture, managed by a DMO, can help to exploit and bundle the possibilities of digitisation. A technical embedding and linking of the content are necessary so that the resources and content can be connected. Due to the decentralised content management that still prevails in many destinations, problems often appear, such as duplication of content in different content silos or duplication of tasks and responsibilities, as well as deviations in content structures between organisations in the respective destination. To avoid this, the interface between the fields of action must be ensured in order to achieve optimal effects (Dwif-Consulting 2017, p. 44). The DMOs of the federal states in Germany deal with these developments in very different ways. A federal state which deals intensively with content architectures is Thuringia. This example is described below.

\subsection{Open Data and Digital Content Architectures as an Opportunity in Tourism: The Example of the Destination Management Organisation Thüringer Tourismus GmbH (TTG)}

In Thuringia, the destination management organisation is currently developing a central content architecture for tourism (ThüCAT), which should was completed this year and has been available as a beta version since summer 2019. The goal is to create a database for all tourism-related content in Thuringia. This content should be made available to all the stakeholders in Thuringia including tourist regions, locations, service providers such as hotels and restaurants (Honig 2019). An important goal is that the information can not only be obtained via the website of the respective institution, but it also reaches the customer on all other channels. This means that ThüCAT information flows to the traveller at all points and in all phases of the customer journey ("Tourismusnetzwerk Thüringen", n.d.). This is a project that can only work by collaborating with all the organisations involved in the creation of touristic offers. Technically, this is realised via a graph database, which then enables the presence of the data on different channels, which in turn means that the tourist can be accompanied as mentioned on all the stages of his or her tour. The semantic labelling and structuring of the data are carried out according to schema. org models, in a format that is universally understandable and machine-readable, which is a basic requirement for processing data by applications that are based on AI. A "knowledge graph" links a wide variety of information such as contact dates, opening times and guided tours in such a way that the guest can get a comprehensive and, if possible, target group-specific or even personalised answer to any of his questions (“Tourismusnetzwerk Thüringen", n.d.). 
Since ThüCAT is filled with content such as images, videos, articles, description texts, geodata, tours and prices that should be available to all players, all the data must be open and accessible. Open data refers to data that is characterised as follows: it may be used, distributed and modified by anyone for any purpose. The only restrictions are to safeguard the origin and openness of this knowledge, for example by naming the author (von Lucke and Geiger 2010, p. 2). The approach of providing open data not only leads to greater transparency and democratic use for society as a whole, but it can also increase the overall economic added value. The decisive factor for this increase is whether the data is used as a strategic core component for social action or not (Sommer 2018, p. 1).

In addition, open data can help transform companies from the inside out by incorporating the digital world and carrying out a so-called digital transformation (Carrara et al. 2015, p. 5). The issues of openness, maturity and value creation are closely linked to open data. The destination management organisation must also deal with these aspects as part of ThüCAT. Based on the data spectrum of the Open Data Institute (ODI), ${ }^{2}$ the ThüCAT data is available on open licence, the highest level at which everyone can freely use and access them. Furthermore, the data should have the highest level of maturity (https://5stardata.info/en/), based on the maturity model by Tim Berners-Lee (2010). In relation to ThüCAT, this means that the data that flows into the system is required in a format that enables automated processing or optimally supports it. The semantic labelling of the data gives the content a future-proof structure that also makes it suitable for the requirements of AI such as voice assistants.

With regard to the added value, the tourism players are aware that it is only the diverse options for subsequent use that make open data work. The management of the data itself has no added value, but only enables the creation of added value for everyone else in the subsequent steps (Dapp et al. 2016, p. 25). The aim should therefore be to ensure that the data is reused using suitable management methods so that applications are created for different costumer segments. The implementation of hackathons to reuse the available data through the integration of external creators seems to make sense. Especially since the tourism stakeholders often lack the corresponding digital know-how, the resources for hiring programmers are scarce. Hackathons and other open innovation methods could thus possibly compensate for the lack of digital know-how in the tourism industry and develop attractive applications for visitors.

\footnotetext{
${ }^{2}$ The Open Data Institute (ODI) was founded in 2012 by the British government. With its help, open data usage should increase, and the institute should be a support in the development of new business models for start-ups. Web inventor Sir Tim Berners-Lee is in charge (Ksoll et al. 2017, p. 10).
} 


\title{
2 Management Methods for Improving the Performance of Destination Management Organisations via the Hackathon
}

\begin{abstract}
A Short Definition
A hackathon is an event in which programmers and others involved in software development work intensively in order to create something new in a short or limited time to contribute to the development of a product (Briscoe and Mulligan 2014, p. 2). The term "hackathon" is a combination of the two words "hack" and "marathon". Hack here means researching software and lines of code. Marathon describes the concentrated and targeted effort to find a solution for the development of software or, in some cases, hardware.
\end{abstract}

\section{Relevance and Application of Hackathons}

The number of Hackathon events is growing faster and faster, and as a result, the hackathon phenomenon has established itself as an effective approach to promoting innovation with technologies in a variety of different areas (Briscoe and Mulligan 2014, p. 1 ff.). With the proliferation of hackathons, the participation of non-technical expertise such as that of marketing experts, business developers and designers has increased (Briscoe and Mulligan 2014, p. 4). Facebook is one of the first companies to decide to continuously integrate this phenomenon into its structure. Today, approximately every two months, many of Facebook's more than 700 engineers meet for a 24-h competition in the company's offices. Many of Facebook's trademarks, including the Like button, started as hackathon projects. The winners will receive posters in a limited edition, on which distinctive phrases such as "In Hack we trust" are shown (Leckart 2012).

\section{The Hackathon Process}

The hackathons often begin with presentations or discussions so that the participants can recognise and convey a common understanding of the problem. Then ideas and suggestions are collected and examined by teams. The team members have mixed backgrounds and skills and form their team autonomously in the process (Richter et al. 2018). A hackathon can usually last between one day and one week (Richter et al. 2018: 115; Briscoe and Mulligan 2014, p. 4; Yueh Perng et al. 2017, p. 2). Depending on the level of funding and organisational resources of the organisers, hackathons can take place in a single city, in several locations or simultaneously all over the world. At the end of the event, a jury will announce the winning prototypes based on how well they have tackled the proposed challenges and what potential they have to be launched as a marketable product. The winners are often rewarded with a cash prize and/or enrolment in incubator and accelerator programmes. ${ }^{3}$ The enrolment comes with prestige, which provides access to broader corporate networks and investment opportunities for venture capitalists or

\footnotetext{
${ }^{3}$ The GroupMe app is a good example of this. It was created as part of a hackathon and raised $\$ 10.6$ million in the first year. Barely one year later, the GroupMe app was sold to Skype for $\$ 85$ million (Leckart 2012; Uffreduzzi 2017, p. 3).
} 
multinational companies (Yueh Perng et al. 2017, p. 3). In the end, the hackathons turn out to be catalysts for new ideas. These events stimulate people intellectually and creatively. The hackathons also require personalities who know how to work quickly with new people in small teams under time pressure. Although not all participants are necessarily successful under such conditions, these events have proven to be successful (Briscoe and Mulligan 2014, p. $11 \mathrm{f}$.). The cost factor must not be forgotten either. In contrast to permanent jobs in product development, where the financial risk is quite high for the organisations, the cost of failures at hackathons is relatively low or zero (Uffreduzzi 2017, p. 6).

\section{Advantages and Disadvantages of Hackathons}

Advantages and disadvantages exist for both the participant and the company side. Advantages for the organisers clearly would be the fast development of ideas and the testing of prototypes, networking and community creation, recruitment and corporate branding (Uffreduzzi 2017, p. 31). In sum, they outweigh the disadvantages like the costs and time an organiser must invest. Hackathons also appear beneficial to the participants. Benefits would be the opportunity to learn and work with new technologies, networking with firms and other participants and the prize that is awarded at the end of the hackathon. Disadvantages would be that the organisers have the right on all ideas generated during the process (intellectual property rights) and that many ideas are not pursued by the organiser.

\section{Hackathons as Part of an Open Innovation Strategy to Enhance Entrepre- neurial Management Behaviours of Organisations}

However, looking at a single management tool is not enough to develop sustainable solutions. Depending on the goal of a hackathon, this is part of an organisation's holistic innovation strategy. This can be carried out, for example, as part of open innovation, which involves the exchange of knowledge across company boundaries (Grichnik et al. 2017, p. 385ff). "Open Innovation is the use of purposive inflows and outflows of knowledge to accelerate internal innovation, and expand the markets for external use of innovation, respectively" (Grichnik et al. 2017, p. 385ff; Chesbrough et al. 2006). Open innovation can be carried out as an "inbound process", in which external knowledge is included in the innovation process, for example to carry out external technology sourcing or to integrate suppliers or customers. This also includes the hackathon. The other direction would be an "outbound process" in which knowledge is commercialised externally if it cannot be used in one's own company, for example licences, technologies, advice. In a "coupled process", the two are connected to independent organisations such as alliances or joint ventures.

For both open innovation as an innovation management method and individual initiatives such as the implementation of a hackathon to be successful for an organisation in the long term, a holistic approach is required that strengthens entrepreneurial action in the respective organisation. A basic orientation can be strategic entrepreneurship as a management approach. This approach implements innovation in the organisation to achieve strategic advantages over competitors (Grichnik et al. 2017, p. 385ff; Kuratko and Audretsch 2009). This can be done in at least five 
different ways: strategic realignment, continuous regeneration, new establishment of a business area (Grichnik et al. 2017, p. 385ff; Covin and Miles 1999) as well as organisational innovation and development of a new business model (Kuratko and Audretsch 2009). A strategic realignment means a fundamental repositioning on the market or against competitors. This can be triggered by new competitors in the market or new technologies. Ongoing regeneration consists of introducing new products or existing products into other markets. The new establishment of a business field means that a company proactively recognises a new product-market combination and acts here as a "first mover". When it comes to organisational renewal, processes and organisational structures are adjusted to achieve efficiency and effectiveness advantages. When developing and implementing a business model, it is a matter of completely breaking down the existing structures and restructuring them (see also Gassmann et al. 2017; Osterwalder and Pigneur 2010). While a hackathon is a unique event, the measures listed form the basis for a sustainable innovation strategy. An organisation needs to reconsider its future role and decide for a way, e.g. a strategic realignment to implement innovation in the overall organisation. An open innovation tool like the hackathon that is embedded in such an entrepreneurial strategy can then increase the innovative strength of an organisation in a "resource-saving" manner by incorporating external knowledge or developing internal knowledge together with partners (Grichnik et al. 2017, p. 385ff).

\section{ThüCAThon: A Hackthon Case Study}

The following section details the case study that was carried out as part of a hackathon. It also looks at how the DMO subsequently dealt with the results, which goals were pursued beforehand and which adjustments have been made in terms of strategic entrepreneurship. The ThüCAThon case study (Yin 2009) was accompanied by interviews with the participants and those responsible for the DMO, evaluations of the websites and pre-questionnaires as well as a 24-h ethnographic observation to see how the teams worked together. The ideas of the three winning teams will also be presented.

The hackathon was prepared and carried out by the Thuringian Ministry of Economic Affairs in cooperation with the DMO of Thuringia. The event took place from 22 to 23 June 2019 in Jena, Thuringia, under the title ThüCAThon. The spacious and modern rooms of the dotSource Company were used for this. Each team was given its own room, each with a large whiteboard. There was also sufficient food available around the clock.

Almost 30 people from different areas of tourism and other fields took part, creating six teams. Registration was free for the participants. They could apply as individuals or be posted on behalf of a company or community. Programmers from the fields of IT and software development, IT consulting, IT and e-commerce and DBS/CRM solutions took part in the event. Two of the programmers also had a background in tourism and astrophysics. The remaining participants came roughly 
equally from the creative industries including the areas of e-commerce, PR marketing, film and animation, consulting, SAP consulting and IT consulting. Students from Thuringian universities and participants from the tourism industry with specialisations in the museum and logistics sector also took part in the process.

The basic data was made available to the teams via the structure of ThüCAT. There were more than 4000 entities with linked data. So that a broader database could be created, a connection was made with other open data such as geography, weather and traffic data. The jury of experts consisted of representatives of the TMWWDG, the TTG and experienced experts from the fields of tourism, digitisation and open data. After all the teams had presented their pitch presentations of the prototypes created at the ThüCAThon, the jury after a long, drawn-out discussion decided which three ideas should be rewarded with prizes.

One of the main goals was to test the ThüCAT database during its development as a beta version and to develop first applications. This hackathon was a good opportunity to network actors at all levels and to see how quickly the incredibly large potential for innovation can be used through digitisation. The ThüCAThon should also serve as proof that the stages created up to that time can be implemented and used to promote digital tourism in Thuringia. Another goal of this hackathon was to attract potential cooperation partners who work in other areas, such as IT specialists, to enable an even more effective implementation of the database.

\section{Process of the Hackathon}

Because it is about a completely new database system that is still in its beta phase, the organisers held a community event the evening before the hackathon, in which there was an explanation of the technical requirements and their limits. On this evening, there was also the opportunity to ask questions, to get to know each other and to start with the team building of the participants. On the first full day after this evening event, the essential part of the work for the participants began and everything went like a "classic" hackathon. First, there was a greeting from the moderator and an introduction and explanation of the format and the procedure. Then the goals of digitisation in tourism were explained. The starting signal was given at 11 a.m. and the 24-h countdown began. First, everyone was allowed to briefly present their idea. All the ideas were collected on a chatboard and categorised by subject area. More than 20 ideas came up. After the BarCamp phase, each participant and each of the organisers were allowed to vote for their three favourites. As a result, six ideas were chosen and a corresponding team was set up with three to six people each. Then the teams had about an hour to develop the original idea and prepare a short pitch. The individual pitches were followed by feedback and questions that continued to lead to interesting discussions. For example, one team changed its entire concept because the other participants recognised the potential in a detail of the basic idea, which led to a significant change in the main approach. The organisers' mentors supported and accompanied the teams on site to better adapt the ideas and results to the existing strategy. Representatives of Join (the agency that was responsible for the technical implementation of ThüCAT) were available for technical questions or problems. Within 
the $24 \mathrm{~h}$, all teams without exception managed to develop their ideas to the maximum, create first prototypes of apps and show their results not only theoretically but also practically. The presentations were public, and each team had approximately six or seven minutes to present their product and answer questions.

There were a total of three award winners as follows.

"First place: The winner of the hackathon was the "What a Day" app team. A personalised, target group-specific travel configurator accompanies the guest interactively along the entire customer journey and always takes current situations or needs into account. The team has managed to integrate all four customer segments listed in the regional tourism strategy and to offer them various organised day tours which guests can adapt as they wish with simple swiping and filter functions.

Second place went to the "Sesame Street" team, which developed an easy way to migrate data from the existing content management systems of tourists to ThüCAT. They also impressed with an entertaining and professional presentation.

Third place went to the team for the "B @ on" project, which proposes to install a so-called dash button for restaurants to signal "We are open" or "We are closed" with the simple click of a button. This smart button then transmits this information directly to ThüCAT, from where it is to be played in real time on all different channels. Restaurants avoid disappointment in front of closed bars; the visitor can always know reliably which nearby restaurants are open"4 (Grinda 2019).

\section{Analysis of the Case Study}

The survey gave the following answers: for almost all participants, the ThüCAThon was the first hackathon ever. Only two of the participants had already attended such events, one of which was a cultural management hackathon in which the format was very different. The other experienced participant was already a hackathon "veteran" with five hackathons under their belt. All the respondents named different motivations for participation. For some, including students, the main motivation was to get to know new people and make contacts that might be helpful later for finding an employer. Others saw this as a way to gather more information about ThüCAT to better understand how it works. Another reason for participating was the challenge of quickly developing something new and learning something new. Others were sent by their company. And everyone also enjoyed working on community projects.

Regarding the question of the extent to which open innovation methods, and in particular the hackathon tool, are suitable for contributing to the development or problem-solving in tourism, the study concluded that the implementation is enormously valuable for tourism. It is the flexibility, the quick reaction to changes and the difficulty in predicting trends in people's travel behaviour that make tourism a branch of the economy that the nature of open and experimental methods is well suited to.

\footnotetext{
${ }^{4}$ Free translation from German by the author, (Grinda 2019).
} 
An examination of the ThüCAThon leads to the following results:

- This hackathon led to many ideas within a short time. Some of these were followed up and completed with specific details during the $24 \mathrm{~h}$. The ThüCAThon has proven to be a method that can be helpful for the rapid development of data-driven projects in tourism.

- Many different actors were integrated into the network, making the whole undertaking more productive. The involvement of many different organisations and people made the proposals very diverse and heterogeneous. The participants brought in their specific knowledge, and if they were lacking expertise in other areas, this was balanced by their motivation and creativity. This type of constructive event is more goal-oriented when various actors are integrated into such a network, because the mixture of different disciplines means that the confluence of the individual specialist qualities in the groups makes it much easier to solve complex questions. Especially due to the short stages and fast rounds of evaluation, both the work dynamics and the motivation remain consistently high over the entire development process. In general, it can be said that the hackathon format offers the opportunity to intensively connect large network structures within a short time and with manageable effort. The role of mentors in a hackathon should not be underestimated, because their presence at ThüCAThon has proven to be an important detail. They helped with any questions or decisions that arose within the groups, because they knew exactly which tourism strategy and which operational goals are pursued by ThüCAT. In this way, they made a decisive contribution to keeping the creative teams on course in all phase of their work, thus guiding the final results towards the goals of the organiser.

- The organisers saved costs thanks to the many ideas collected and prototypes created within $24 \mathrm{~h}$. As already mentioned in the case study, more than 20 ideas were collected at ThüCAThon, mostly from people who did not get any money for it, apart from the three award winners at the end. Of course, money is spent on the organisation of such an event, but considerable results are achieved, from starting with the idea, continuing through the collaboration of IT, marketing and tourism experts to creating a prototype. All of these components would burden a company's budget significantly in conventional, i.e. closed processes, especially if they had to pay several teams at once. However, according to the participants, the prize money was not their main reason for participating in the ThüCAThon, instead, curiosity about this new construct and the opportunities for networking were the strongest motivations.

- The organisers very quickly received expert and constructive feedback for the beta version of ThüCAT from many different specialists at the current time. The hackathon is not only a good approach for collecting ideas. A completely new system, namely ThüCAT, was shown with its capabilities in the beta version. This enabled the participants to get to know ThüCAT and to make their comments or recommendations. The ThüCAT was supplied with the data, it was then checked to see whether it could work well, and finally the first product developments in the form of application prototypes were made available based on ThüCAT. 
However, there are also learnings and traps that should be avoided: for future hackathons, a more generous prize for the winners could be considered in order to continue to attract even more capable and motivated people to such events. Another problem, already mentioned above, is that ideas have not been not pursued by the organiser. An interview with one of the managers responsible at the DMO half a year after the event showed that there is a need to follow up on the sustainability or recycling of ideas. So far, the ideas from the ThüCAThon have not been developed, but are in the drawer or only on the website (Grinda 2019). However, this is also due to the development process that is still in full swing. The interview partner described the future role of the DMO as follows: the hackathon was a first test balloon for such a format in Thuringian tourism, with thoroughly positive feedback from the participants. After the current project phase of the technical creation of ThüCAT with all its components, including graph database, website kit, search engine, editor for recording and interface connection, the collaboration phase begins. On the one hand, the goal is to find interested parties for the data: here among others the creative industries play a role, developing innovative technical solutions and formats and using tourist data from ThüCAT. It does not have to be a purely tourist product; sometimes only a small part of the tourism data is used. Here the development of ideas from the hackathon could be an approach to force concrete implementations. On the other hand, the goal is also to use the network to link with other open databases relevant to tourist use, for example weather data in conjunction with appropriate excursion tips. The role of the DMO will lie in checking the Thuringian data pool regarding topicality, completeness and data quality, as well as in the technical support of the system and the search for the most attractive multipliers such as $\operatorname{ADAC}^{5}$ (Allgemeine Deutsche Automobil-Club e. V.), AirBnB, WWF or others for high-reach draws. As our interview partner from the DMO states: "In the course of product development, I see great opportunities to create useful use cases together with the tourism partners in Thuringia and to launch model projects. The TTG will act in an advisory and supportive manner in the sense of networking. We rarely, or not at all, commission our own innovative applications." ${ }^{, 6}$

\section{Conclusion}

In the beginning, we have posed the question of how new digital technologies and management methods must be implemented in destination management organisations so that they generate sustainable competitive advantages and customer benefits for the respective travel destination. We also intended to find out if an open data hackathon is a suitable approach to help ensure the competitiveness of tourist destinations. The answer is twofold: firstly, from our case study we can subsume that a hackathon can be very useful for producing many ideas within a short time. It

\footnotetext{
${ }^{5}$ The ADAC is an automobile association in Germany. It is the equivalent of RAC or AA in UK. ${ }^{6}$ Translation from an interview with the team leader of the development and implementation of the ThüCAT at TTG.
} 
is also a good method to integrate different actors into a network in order to make the process more productive. Especially, the role of the mentors is important to align the ideas to the overall tourism strategy. Another aspect is the cost-saving opportunity when creating prototypes compared to developing them inhouse or with a service provider. Also the feedback for the beta version of the ThüCAT has been extremely useful for the DMO.

However, when looking at the overall goal of achieving customer benefits and ensuring the competitiveness of a tourist destination, a DMO must additionally guarantee a high quality of the results and the sustainability of the ideas produced during a hackathon. From our case study, we have learned that for ensuring a high quality of ideas produced, it would be recommendable to award more generous prizes for the winners in order to attract even more capable and motivated people especially programmers. Giving the aspect of sustainability, many ideas are not pursued by organisers of hackathons. This is also the case for the ThüCAThon. It must be shown how ideas deriving from hackathons are pursued, refined and applied, and their effects on the market must be measured. It is important to realise that with the new approaches to data provision and data processing, new holistic management methods are necessary. Making the best use of all technical innovations and meeting new customer demands can only be achieved through adaptations in organisational strategy and rethinking in management. A hackathon as an entrepreneurial management tool must therefore be embedded in an overall approach to strategic entrepreneurship (see Fig. 1).

However, from the case study, we have learned that the DMO in Thuringia is currently actively rethinking and developing its role in the renewal process (organisational innovation, see Fig. 1). For this purpose, the DMO has created a competence centre for the implementation of ThüCAT, which takes on the responsibility of guiding and distributing all content that comes from partners, tourism organisations at the regional and local level and from tourism service providers at the company level. This means that not every single company has to go digital, but the TTG develops concepts and solutions, implements them and involves all actors in Thuringia in them or passes the results on to them (Dwif-Consulting 2017: $45 \mathrm{ff}$.). In view of the statements made by those responsible, the DMO is pursuing an open innovation strategy in which active "inbound" processes are carried out by integrating creative people by using tools such as hackathons. Furthermore, the DMO follows "outbound" processes because it is looking for interested parties for the data available and sees itself as a platform that ensures the quality and up-to-datedness of the data and encourages approaches to its use. Following this approach, the DMO could also try to find partners who are willing to test and bring applications to the market (see Fig. 1, steps $7 \& 8$ ). It then follows an outbound process, following its new role as a smart data platform. Strategic entrepreneurship approaches can help to reclassify and define this role. When considering the DMO presented here, a strategic realignment (see Fig. 1) is already taking place in order to reposition itself against competitors in the digital economy such as Google or Facebook and powerful travel portals like booking.com or Expedia. This realignment was triggered by the technologies shown in this 


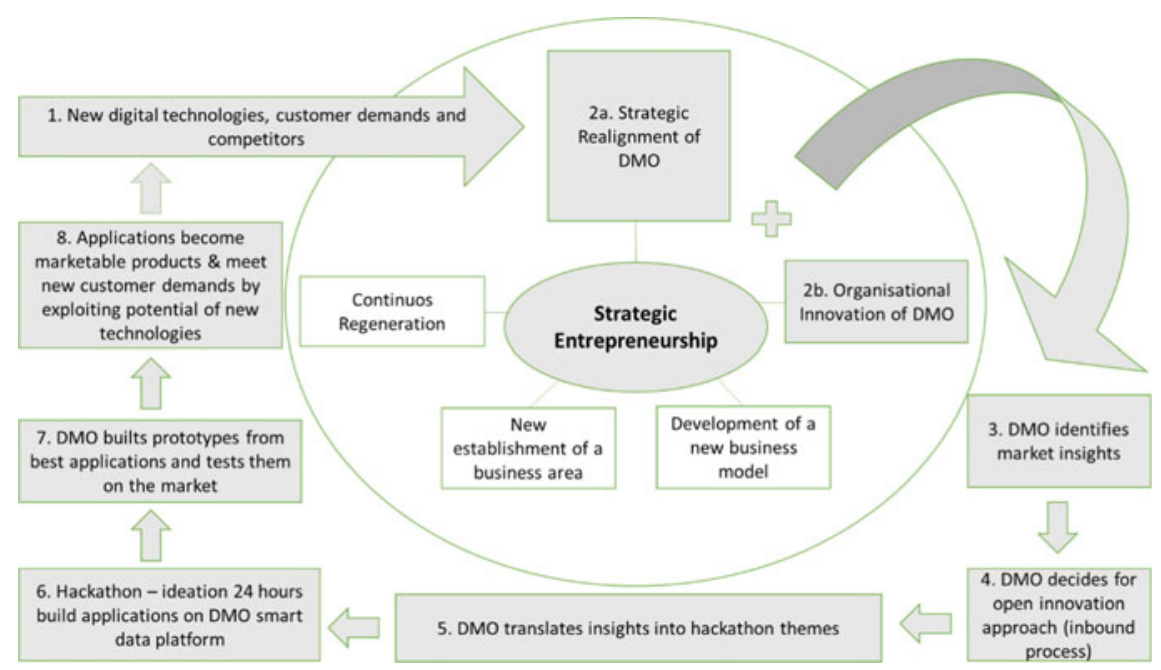

Fig. 1 Eight steps for implementing hackathons in DMO's. Learning's from the ThüCAThon case study

chapter. The ordinary channels such as the destination management website move into the background. The focus is on the content or data, which is structured by schema.org and made freely available in the sense of open data. This not only benefits the powerful platform providers like Google, but as the hackathon showed all participants in the market can use the data and, based on this, develop their own business ideas, including individual creatives and start-ups. Nevertheless, the DMO uses the power of Google and Facebook and their channels to bring their content to the guest. The visibility of the DMO increases compared to the current situation, and the DMO can influence the quality of the data.

The strategic realignment is radical and entails a change in the classic tasks of a DMO. The DMO itself becomes a smart data platform and must therefore also adapt its processes and structures in order to achieve efficiency and effectiveness advantages. Future research work can actively accompany these developments. Action research methods in which researchers and practitioners cooperate would be suitable. It would also be interesting to examine the effects on other market participants. Is a hackathon suitable to stimulate the formation of startup teams that use the available data for own business ideas, or to pursue projects in the company in the sense of intrapreneurship? Will DMOs develop their own applications in the future although they do not currently see their tasks in the area of customer applications? These and other questions need to be answered as part of the new opportunities and challenges. The potential of hackathons and other open innovative approaches in tourism is far from being exhausted, in fact it is only just beginning, and it can be expected that it will be used to an increasing extent in the future. The aspects of cost and time savings through open innovation with constant 
feedback, avoiding dead ends in development, quick error correction and enormous capacity for change during the ongoing development process are just too valuable to ignore.

\section{References}

Briscoe, G., \& Mulligan, C. (2014). Digital innovation: The Hackathon phenomenon. London: Creative works London. Retrieved from https://pdfs.semanticscholar.org/cb8e/ 44ec1bcd6062e5fccafb6837030be334731d.pdf?_ga=2.252250953.1703906457.15873005721942274566.1587300572.

Carrara, W., Fischer, S., Oudkerk, F., van Steenbergen, E., \& Tinholt, D. (2015). Analytical report 1: Digital transformation. Retrieved from https://www.europeandataportal.eu/sites/default/ files/edp_analytical_report_n1_-_digital_transformation.pdf. Accessed 11 July 2019.

Chesbrough, H., Vanhaverbeke, W., \& West, J. (Eds.). (2006). Open innovation: Researching a new paradigm. Oxford University Press on Demand.

Covin, J. G., \& Miles, M. P. (1999). Corporate entrepreneurship and the pursuit of competitive advantage. Entrepreneurship Theory and Practice, 23(3), 47-63.

Dapp, M., Balta, D., Palmetshofer, W., Krcmar, H., \& Kuzev, P. (Eds.). (2016). Open data. The benefits. Das volkswirtschaftliche Potential für Deutschland. Berlin: Konrad-AdenauerStiftung e.V., Sankt Augustin. Retrieved from https://www.kas.de/c/document_library/get_ file?uuid=3fbb9ec5-096c-076e-1cc4-473cd84784df\&groupId=252038. Accessed 11 July 2019.

Dwif Consulting. (2017). Tourismusstrategie Thüringen 2025. Berlin. Retrieved from https://wirtschaft.thueringen.de/fileadmin/user_upload/Publikationen/Pub-TourismusstrategieThueringen-2025.pdf. Accessed 15 Mar 2020.

Freyer, W. (2015). Tourismus: Einführung in die Fremdenverkehrsökonomie. Berlin: De Gruyter Verlag.

Gassmann, O., Frankenberger, K., \& Csik, M. (2017). Geschäftsmodelle entwickeln: 55 innovative Konzepte mit dem St. Galler business model navigator. Carl Hanser Verlag GmbH Co KG.

German National Tourist Board. (n.d.). ThüCAT-Das Konzept eines digitalen Tourismus. Retrieved from https://open-data-germany.org/thuecat-das-konzept-eines-digitalen-tourismus/. Accessed 15 Mar 2020.

Grichnik, D., Brettel, M., Koropp, C., \& Mauer, R. (2017). Entrepreneurship: unternehmerisches Denken. Schäffer-Poeschel: Entscheiden und Handeln in innovativen und technologieorientierten Unternehmen.

Grinda, I. (2019). Thüringens erster Hackathon im Tourismus. Retrieved from https://thueringen. tourismusnetzwerk.info/2019/06/24/thueringens-erster-hackathon-im-tourismus/. Accessed 15 Mar 2020.

Hauer, L. (2020). Strukturierte Daten: Mehr Aufmerksamkeit in den SERPs. Retrieved from https://www.luna-park.de/blog/29207-strukturierte-daten/. Accessed 15 Mar 2020.

Honig, K. (2019). Best practice - Open data in Thüringen. Retrieved from https://open-datagermany.org/best-practice-open-data-in-thueringen/. Accessed 3 Apr 2020.

Horster, E., \& Foltin, C. (2020). Smart Destinations-Vernetzung von analoger und digitaler Welt. Retrieved from https://www.neusta-ds.de/blog/author/prof-dr-eric-horster-und-constantinfoltin/. Accessed 15 Mar 2020.

Horster, E., \& Kärle, E. (2019a). Linked open data und Künstliche Intelligenz. The perfect Match? Retrieved from https://open-data-germany.org/linked-open-data-und-kuenstliche-intelligenz/. Accessed 15 Mar 2020.

Horster, E., \& Kärle, E. (2019b). Knowledge Graphen. Ein Spiegel der (touristischen) Wirklichkeit. Retrieved from https://open-data-germany.org/knowledge-graphen/. Accessed 15 Mar 2020. 
Horster, E., \& Kärle, E. (2019c). Das Headless Web. Datenmanagement modular denken. Retrieved from https://open-data-germany.org/headless-web/. Accessed 15 Mar 2020.

IGI Global. (n.d.). Tourism knowledge. Retrieved from https://www.igi-global.com/dictionary/ tourism-knowledge-destination/34186. Accessed 3 Apr 2020.

Keller, B., Möhring, M., Toni, M., Di Pietro, L., \& Schmidt, R. (2017). Data-centered platforms in tourism: Advantages and challenges for digital enterprise architecture. In W. Abramowicz, R. Alt, \& B. Franczyk (Eds.), Business information systems workshops. BIS 2016. Lecture notes in business information processing (Vol. 263). Cham: Springer.

Kinlan, P. (2016). The headless web. Retrieved from https://paul.kinlan.me/the-headless-web/. Accessed 15 Mar 2020.

Ksoll, W., Schildhauer, T., \& Beck, A. (2017). Open data-Wertschöpfung im digitalen Zeitalter. Retrieved from https://www.bertelsmann-stiftung.de/fileadmin/files/Projekte/Smart_Country/ OpenData_2017_final.pdf. Accessed 20 July 2019.

Kuratko, D. F., \& Audretsch, D. B. (2009). Strategic entrepreneurship: Exploring different perspectives of an emerging concept. Entrepreneurship Theory and Practice, 33(1), 1-17.

Leckart, S. (2012). The Hackathon is on: Pitching and programming the next killer app. Retrieved from https://www.wired.com/2012/02/ff_hackathons/. Accessed 21 June 2019.

Osterwalder, A., \& Pigneur, Y. (2010). Business model generation: A handbook for visionaries, game changers, and challengers. New York: Wiley.

Paulheim, H. (2016). Knowledge graph refinement: A survey of approaches and evaluation methods. semantic Web 0 (2016) 1-01.IOS. Retrieved from: Press. http://www.semantic-webjournal.net/system/files/swj1167.pdf. Accessed 15 Mar 2020.

Richter, N., Schildhauer, T., \& Jackson, P. (2018). Meeting the innovation challenge: Agile Processes for established organizations. In N. Richter, P. Jackson, \& T. Schildhauer (Eds.), Entrepreneurial innovation and leadership: Preparing for a digital future. Cham: Palgrave Pivot.

Samochowiec, J., Kwiatkowski, M., \& Breit, S. (2019). Unterwegs mit smarten Assistenten. Ein Szenario zum Reisen der Zukunft. Retrieved from: Studie. https://www.gdi.ch/de/ publikationen/studien-buecher/unterwegs-mit-smarten-assistenten. Accessed 15 Mar 2020.

Semantify. (n.d.). https://semantify.it/. Accessed 15 Mar 2020.

Sommer, G. (2018). Herausforderungen und Chancen einer offenen, digitalen Dateninfrastruktur im Tourismus. Ergebnisse des ersten Think Tanks zum Thema „Open Data im Tourismus“ sowie aktuelle Entwicklungen. Retrieved from https://okfn.de/files/blog/2018/08/ ThinkTank2017_Whitepaper_formatiert_Final.pdf. Accessed 20 June 2019.

Statista. (2019). Was sind aktuell die größten Hindernisse in der Implementierung digitaler Instrumente in Ihrer Destination? Retrieved from https://de.statista.com/statistik/daten/studie/ 1079727/umfrage/hindernisse-in-der-implementierung-digitaler-instrumente-im-bereich-tourismus/. Accessed 15 Mar 2020.

Stichbury, J. (2017). WTF is a knowledge graph? Unpicking a tangle of terminology to conclude it's semantic, smart and alive. Retrieved from https://www.hackernoon.com/wtf-is-aknowledge-graph-a16603a1a25f. Accessed 11 July 2019.

Tourismuszukunft. (n.d.). Digitalisierung im Tourismus. Retrieved from https://www. tourismuszukunft.de/wp-content/uploads/2020/03/0403-Tourismuszukunft-Infografik-2020. pdf. Accessed 15 Mar 2020.

Tourismusnetzwerk Thüringen. (n.d.). Thüringer Content Architektur Tourismus. ThüCAT. https://thueringen.tourismusnetzwerk.info/inhalte/digitales-content/thuecat/. Accessed 15 June 2019.

Uffreduzzi, M. (2017). Hackathon as emerging innovation practice: Exploring opportunities and challenges through 8 in-depth case studies (Master Thesis). Retrieved from https://www. politesi.polimi.it/bitstream/10589/137237/5/Hackathon\%20as\%20Emerging\%20Innovation\% 20Practice.pdf. Accessed 15 June 2019. 
Von Lucke, J., \& Geiger, C.P. (2010). Open government data. Frei verfügbare Daten des öffentlichen Sektors. Zeppelin University, Friedrichshafen, Bodensee. Retrieved from https:// www.zu.de/institute/togi/assets/pdf/TICC-101203-OpenGovernmentData-V1.pdf. Accessed 7 Sep 2019.

Yachin, J. M. (2018). The 'customer journey': Learning from customers in tourism experience encounters. Tourism Management Perspectives, 28, 201-210.

Yin, R. K. (2009). Case study research. Design and methods, 4th edn. Los Angeles: Sage (Applied social research methods series, 5).

Yueh Perng, S., Kitchin, R., \& Mac Donncha, D. (2017). Hackathons, entrepreneurship and the passionate making of smart cities: The Programmable City Working Paper 28.

Open Access This chapter is licensed under the terms of the Creative Commons Attribution 4.0 International License (http://creativecommons.org/licenses/by/4.0/), which permits use, sharing, adaptation, distribution and reproduction in any medium or format, as long as you give appropriate credit to the original author(s) and the source, provide a link to the Creative Commons license and indicate if changes were made.

The images or other third party material in this chapter are included in the chapter's Creative Commons license, unless indicated otherwise in a credit line to the material. If material is not included in the chapter's Creative Commons license and your intended use is not permitted by statutory regulation or exceeds the permitted use, you will need to obtain permission directly from the copyright holder.

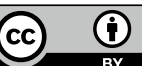

